\title{
The Effect of Social Feature Quality on the Social Commerce System
}

\author{
Nona M. Nistah ${ }^{1}$, Suaini Sura ${ }^{3}$ \\ Faculty Computing and Informatics \\ University Malaysia Sabah \\ Labuan, Malaysia
}

\author{
Maryati Mohd. Yusof ${ }^{2}$ \\ Faculty of Information Science and \\ Technology, Universiti Kebangsaan \\ Malaysia Bangi, Malaysia
}

\author{
Ook Lee ${ }^{4}$ \\ Department of Information Systems \\ Hanyang University \\ Seoul, R.O. Korea
}

\begin{abstract}
The emergence of social networks has triggered the evolution of e-commerce to what is now known as socialcommerce (s-commerce). However, s-commerce users experience problems related to its social features that affect s-commerce effectiveness. Therefore, the paper examines the effect of social feature quality (SFQ) determinants on s-commerce from customer perspective by adapting the information systems success model. A total of 220 online survey responses were analyzed by using confirmatory factor analysis and the structural equitation model to test the proposed model. SFQ shows a significant effect on perceived usefulness and customer satisfaction with an s-commerce system, whereas relationship support quality shows a significant effect on perceived usefulness and customer satisfaction with an s-commerce system but not on social support. A significant relationship is also identified among perceived usefulness, customer satisfaction, and net benefits of an s-commerce system.
\end{abstract}

Keywords-Social feature quality; relationship support; social support; s-commerce; e-commerce; customer satisfaction

\section{INTRODUCTION}

The increasing interest in Web 2.0 and social media has triggered the evolution of conventional electronic commerce (e-commerce) to social commerce (s-commerce). S-commerce has various definitions, with its essence lying in social media, community, and commerce activities [1]. Therefore, scommerce can be defined as a form of an online business that combines e-commerce with "community" to facilitate the consumers' online commerce activities (i.e., selling and buying) [2]. In this context, the community is supported by their use of social media or Internet-based applications, including social networking sites (SNS), blogs, and videos (YouTube), that are designed to attract users (i.e., customers). Therefore, in the s-commerce context, Internet-based applications are used to accomplish commerce-related activities, including buying, selling, distributing information about products and services, and sharing online shopping experiences [3].

Soon after its emergence, SNS has attracted usage as an scommerce platform where customers can engage in online shopping [3]. Previous studies show that using SNS as a business platform greatly contributes to s-commerce revenue. For example, Wong [4] reported that $40 \%$ of Malaysian Internet users use SNS for online shopping and $51 \%$ of them admitted that they started shopping online after their exposure to SNS (i.e., Facebook). These figures indicate that SNS is a well-accepted online shopping platform that can persuade people to purchase products. Despite the potential benefits of SNS such as saving time and money, customers are often exposed to problems related to the social features of scommerce, including direct and indirect communication, usergenerated content (UGC), and interaction in online communities, thereby influencing the reputation of SNS-based commerce and the customer satisfaction [5-8]. Customer satisfaction can influence the level of system use and vice versa as well as encourage users to increase their system use. Meanwhile, an effective system use can lead to customer satisfaction depending on the ability of users in maximizing their utilization of the available features and functions in the system [9]. These effects, in turn, may lead to customer loyalty and repurchase behavior, which will enable sellers to establish and maintain their relationships with their customers while gaining profit. Therefore, the social feature quality (SFQ) determinants that affect customer satisfaction must be understood from the customers' perspective. Given that scommerce is still developing as a new sales platform, some studies have already begun to examine this field, particularly its social features. We adapt the information systems (IS) success model [10] to examine the effects of these social features on the customer satisfaction with s-commerce from the customers' perspective.

This paper is organized as follows. Section II presents the theoretical background of the study, the model utilized in the previous literature to investigate the customer satisfaction with s-commerce research model, and hypotheses. Section III explains the research methodology and Section IV reports the findings and offers the discussion. Section V provides the conclusion.

\section{RELATED WORKS}

\section{A. S-Commerce and $S F Q$}

An s-commerce community is supported by social media where customers go beyond seller information and directly or indirectly interact with other customers when making their final purchase decisions. In this case, social interaction plays an important role in s-commerce platforms and produces different value for businesses [6,11]. Apart from social interaction, UGC implies that users or consumers can create and publish their own content to help other users make purchase decisions in an online marketplace [12]. Therefore, social features play important roles in s-commerce. These 
features promote "socializing" behavior or community interactions that can influence the online shopping decisions of other members (i.e., customers) [6,11]. Socializing is an essential foundation of s-commerce [5]. SFQ is mainly measured based on social support and relationship support $[5,6,11]$, both of which have significant effects on the behavior of users toward s-commerce, which in turn can increase the perceived usefulness and customer satisfaction with SNS-based commerce.

Social support explains social supportive communication in an online context (i.e., SNS). The emergence of SNS functions has allowed community members to go online shopping while simultaneously socializing with other members or seeking help from other SNS functions (e.g., ratings and recommendations) when making purchase decisions $[6,13]$. SNS also provides community members with an important source of social support through commercial information sharing, which provides these members a sense of belonging and appreciation, thereby motivating them to participate in s-commerce discussion. Consequently, the relationships among the community members are enhanced, thereby increasing their confidence to shop online via SNSbased commerce [5].

The participation of customers in the community [14] can increase their commitment, promote long-term relationships $[5,6,11]$, and build their loyalty to the online community and the SNS-based commerce system. Accordingly, sellers can maintain their relationship with their customers while gaining profit. Previous studies (e.g., [6,7,14] define trust as an important element in ensuring relationship quality, that is, trust serves as the foundation of any stable relationship. In the context of SNS-based commerce, trust among members is built through interaction. When the trust among members grows, these members perceive SNS-based commerce as a trusted platform that they can use to shop online. Meanwhile, relationship, which is an intrinsic constituent of relationship quality, is built upon communication. In other words, the lack of communication may lead to a poor relationship $[15,16]$. Therefore, in this study, communication is considered a measure of relationship. Relationship quality is a strong determinant of an individual's s-commerce intention and is related to the perceived usefulness and customer satisfaction with an s-commerce system.

\section{B. IS Success Model}

E-commerce is considered a part of IS as it uses information and communication technologies to facilitate, execute, and process its business functions [17]. Therefore, the IS success model [17] has been widely adopted in e-commerce research (Fig. 1). Several minor refinements were applied to the original model to define the possible measures for each of its dimensions and to suit the e-commerce context $[10,17]$. This model focuses on three variables, (e.g., system quality, information quality, and service quality) interrelated with the use, customer satisfaction, and net benefits of the system.

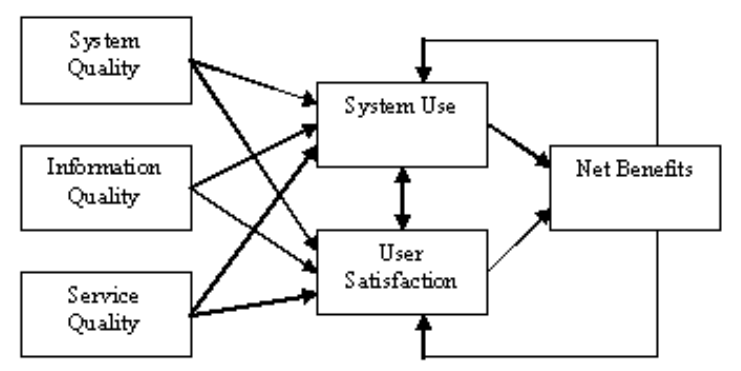

Fig. 1. IS Success Model [10]

Given the ability of the IS success model to measure the ecommerce system, many studies (e.g., [5,6]) have extended and adapted this model to investigate the customer satisfaction with s-commerce by adding the social feature element.

Previous studies have employed various terms to refer to the use dimension, including perceived usefulness. Some have argued that the use dimension represents behavior, thereby making this dimension highly appropriate for process models; by contrast, other researchers contend that the perceived usefulness dimension represents attitude, thereby making this dimension most appropriate for causal models [18]. The high perceived usefulness of e-commerce results in customer satisfaction. Rai et al. [19] validated the above constructs as meaningful measures of IS success depending on the type of delivery. In sum, perceived usefulness is appropriate when considering an attitude derived from perceptions toward past IS use [19,20], whereas the use construct is more appropriate for measuring an actual behavior than the perception toward a behavior [10,19]. Accordingly, we employed perceived usefulness to measure how customers view the potential benefits of s-commerce.

\section{Research Model and Hypothesis Development}

Our research model was adapted from the IS success [17]. We focused on the relationship among SFQ, perceived usefulness, and customer satisfaction; all the other dimensions of IS success are beyond the scope of our paper. We used customer satisfaction instead of user satisfaction after considering the customer e-commerce satisfaction construct proposed by Molla and Licker [21]. We also used the perceived usefulness construct [18] given that our main objective is to measure attitudes instead of behaviors [19,20]. We added the SFQ element to the left side of the model and excluded the other elements in the IS success model, including system quality, information quality, and service quality, to adapt our model to the objectives and scope of our paper $[6,20]$. The research model is presented in Fig. 2 .

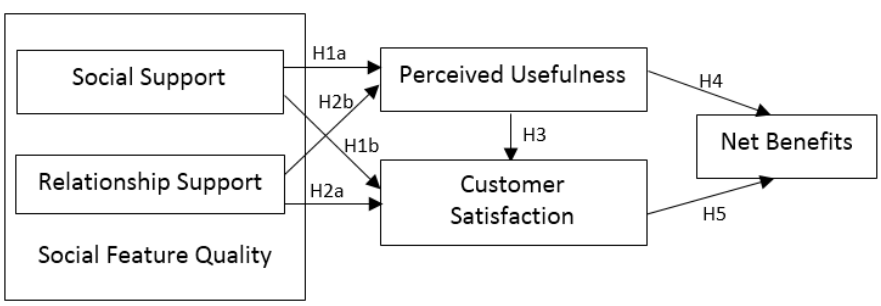

Fig. 2. Research Model.

We greatly appreciate funding received from the Universiti Kebangsaan Malaysia (DIP-2016-033). 
SFQ is explained by four constructs:

Social support is related to a social supportive communication in an online context (i.e., SNS). This construct is often measured through information support $[5,6,13]$, emotional support, and normative support [22]. Therefore, we propose

H1a: Social support has a significant effect on the perceived usefulness of s-commerce.

H1b: Social support has a significant effect on the customer satisfaction with s-commerce.

Relationship support refers to the extent to which the members involved in a communication-based relationship trust one another and are committed to their community. Relationship support is measured through trust, confidence, commitment [5,6,11], and communication [16]. This construct is also considered as one of the strongest determinants of scommerce intention that is related to the usefulness and customer satisfaction with an s-commerce [5,6]. Therefore, we propose

H2a: Relationship support has a significant effect on the perceived usefulness of s-commerce.

H2b: Relationship support has a significant effect on the customer satisfaction with s-commerce.

Perceived usefulness refers to the degree to which a user believes that using a system will enhance his/her job performance $[19,20]$. In other words, customers with a higher level of perceived usefulness experience greater satisfaction [23]. Perceived usefulness also refers to the benefits that users are expecting to receive after using a particular system. In this case, perceived usefulness is concerned with the future (net) benefits of a system. The empirical evidence related to ecommerce $[14,24]$ supports the relationships of perceived usefulness with customer satisfaction and net benefits. Therefore, we propose

H3: Perceived usefulness has a significant effect on the customer satisfaction with s-commerce.

H4: Perceived usefulness has a significant effect on the net benefits of s-commerce.

Customer satisfaction refers to how customers rate their commerce experience in using s-commerce [21]. When customers experience pleasure, they tend to be highly satisfied [20]. In their individual-level analysis, customer satisfaction offers a moderate to strong degree of support for the net benefits of s-commerce [25]. Therefore, we propose

H5: Customer satisfaction has a significant effect on the net benefits of s-commerce.

\section{METHOD}

\section{A. Data Collection}

A total of 248 respondents participated in our survey. All these respondents were from Malaysia and had previously engaged in online shopping via SNS platforms. We used the snowball sampling technique in selecting our sample and posted online questionnaires on various SNSs, including Facebook and Instagram. This questionnaire was divided into two main parts, with the first part asking for the demographic information of the respondents and the second part asking for the SFQ attribute constructs featured in our model. All questions were measured using a seven-point Likert-type scale ranging from "strongly disagree" (1) to "strongly agree" (7). Upon removing those questionnaires with incomplete and duplicate responses, 220 responses were analyzed quantitatively via structural equation modeling.

\section{B. Data Analysis}

We performed confirmatory factor analysis to validate our model. We then tested the validity and reliability of our measurement items, followed by hypothesis testing analyses.

\section{RESUltS}

1) Demographic characteristics: A total of 128 (58.2\%) female and $92(41.8 \%)$ male respondents participated in this survey. The majority of these respondents $(80.5 \%)$ were university students aged between 20 and 29 years. Around $73.2 \%$ of these respondents were pursuing bachelor's degree courses. Facebook was the most popular SNS used by these respondents, and only one respondent did not have a Facebook account. Most of the respondents (78\%) spend more than 2 hours a day on their SNSs. Therefore, all respondents were assumed to be familiar with using SNS as an online shopping platform

2) Reliability and validity of measurement items: Based on the confirmatory factor analysis, the measurement model exhibited an acceptable to fair fitness with the collected data $\left(\chi 2=78.822, \mathrm{df}=25, \chi^{2} / \mathrm{df}=3.153, \mathrm{GFI}=0.947\right.$, AGFI $=$ $0.893, \mathrm{NFI}=0.974, \mathrm{CFI}=0.982$, and RMSEA $=0.078)$. We then tested the validity and reliability of our measurement items. All constructs are valid with composite reliabilities of above 0.80 and average variance extracted of above 0.50 [26].

3) Hypothesis testing analyses: The findings illustrated in Fig. 3 support hypotheses H2a, H2b, H3, H4, and H5. Specifically, relationship support has a significant effect on the perceived usefulness and customer satisfaction with scommerce, perceived usefulness has a significant effect on customer satisfaction with s-commerce, and both perceived usefulness and customer satisfaction have significant effects on the net benefits of s-commerce. Overall, SFQ has a significant effect on perceived usefulness $\left(0.175^{* * *}\right)$ and customer satisfaction $\left(0.198^{* * *}\right)$.

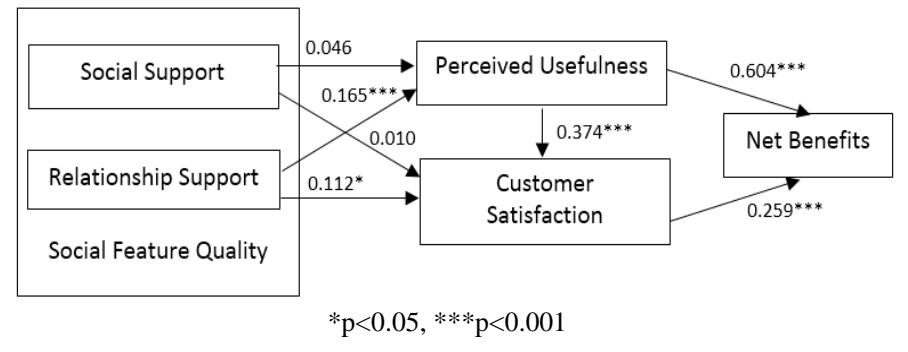

Fig. 3. Hypotheses Testing Results. 
Social aspect is an essential foundation of s-commerce. We measure SFQ by using the social support and relationship support constructs following the suggestions of previous studies (e.g. $[5,6,27,28])$. Overall, SFQ shows a significant relationship with perceived usefulness and customer satisfaction with SNS-based commerce. These findings agree with previous studies $[8,29]$ and underscore the importance of social aspect in supporting the interactions and strengthening the relationships among SNS members as they exchange information comfortably and conveniently [5,30].

Although SFQ showed significant positive associations with both perceived usefulness and customer satisfaction with s-commerce, we obtain different results for the individual construct. Surprisingly, only relationship support showed a positive relationship with perceived usefulness and customer satisfaction with s-based commerce, which contradicts the findings of Liang et al. [5], Hajli [6], and Chen and Shen [14] and implies that both social support and relationship support influence s-commerce intention. Our findings show the significant positive relationship of relationship support with perceived usefulness and customer satisfaction, thereby proving that relationship support represents the crucial elements of SNS-based commerce, including consumer trust, confidence, and commitment. This finding is consistent with studies which suggest that after SNS-based commerce consumers trust an online community member, they can confidently engage in SNS-based commerce, begin to realize its usefulness, and consequently increase their satisfaction with this form of commerce [8,11,31]. As a result, the relationship among online community members is strengthened along with their commitment and customer loyalty, which in turn can lead to a boost in sales $[6,8]$.

However, social support quality shows an insignificant relationship with perceived usefulness and customer satisfaction with SNS-based commerce, which aligns with two studies $[8,29]$ but contradicts the results of other studies $[5,6,14]$. In other words, social support, including emotional and informational support, is not a prerequisite for SNS-based commerce and may instead be related to the quality of information itself. Information overload and difficulty in controlling information may cause confusion among customers [32], thereby raising the concern of whether information can actually support customers when making purchasing decisions in the context of SNS-based commerce. Trust also presents one of the greatest challenges to emotional support $[6,14]$. Specifically, emotional support is weakened if online community members do not trust one another. In this regard, although the community members show trust to one another, their trust level is low, thereby explaining the insignificant relationship of social support quality with perceived usefulness and customer satisfaction with SNSbased commerce.
The insignificant relationship of social support with perceived usefulness and customer satisfaction with SNSbased commerce does not suggest that social support is irrelevant to SNS-based commerce. Instead, social support complements relationship support, that is, social support serves as a core foundation for the social interaction provided by SNS-based commerce and plays a key role in building relationships among online community members. Consistent with previous studies $[7,10,25]$ we find a positive relationship among perceived usefulness, customer satisfaction, and net benefits of SNS-based commerce. A high level of perceived usefulness leads to customer satisfaction [24], whereas a high perceived usefulness and customer satisfaction maximize the net benefits gained by customers. Therefore, customers benefit from their use of SNS-based commerce when they are satisfied and perceive this system as useful.

\section{CONCLUSION}

Our findings contribute to IS theory and practice by providing some guidelines for monitoring and measuring scommerce social feature quality. Emphasis can be given to a particular measure depending on the study context. However, several limitations of this research must be noted. First, although social support and relationship support have many attributes, we only use certain attributes that we believe to be crucial for the context of our study. Second, we validated our research model by using data from Malaysia. Therefore, our model may have limited generalizability for other countries due to cultural, societal, and situational differences. Third, we performed our research in the e-commerce (C2C and B2C) domain, which is related to s-commerce. Therefore, our study might not represent all domains of s-commerce. Despite these limitations, we believe that our study yields important and reasonable findings that can provide directions to other researchers in the s-commerce and IS-related areas. To provide insightful findings, further research must be conducted with an expanded sample, additional e-commerce domains, and additional SFQ characteristics.

\section{ACKNOWLEDGMENT}

We thank UKM and UMS for this joint collaboration.

\section{REFERENCES}

[1] T.P. Liang and E. Turban. "Introduction to the special issue social commerce: a research framework for social commerce", Int J Electron Com, vol. 16, no. 2, pp. 5-14, 2011.

[2] E. Turban, C. Pollard and G. Wood. "Information Technology for Management", 11th edition. Singapore: John Wiley and Sons (Asia) Pte Ltd., 2018.

[3] X. Lin, Y. Li and X. Wang. "Social commerce research: definition, research themes and the trends". Int J Info Manage, vol. 37, no. 3, pp. 190-201, 2017.

[4] C.K. Wong, "E-commerce infographic: understanding online shopper in Malaysia”. E-Commerce MILO, 2014. 
[5] T.P. Liang., Y.T. Ho, Y.W. Li and E. Turban, "What drives social commerce: the role of social support and relationship quality". Int J Electron Com, vol. 16, no.2, pp. 69-90. 2012.

[6] N. Hajli, X. Lin, M.S. Featherman and Y.Wang, "Social word of mouth: how trust develops in the market". Int J Market Res, vol. 56, no. 5, pp. 673-689, 2014.

[7] P. Lal. "Analyzing determinants influencing an individual's intention to use social commerce website" Future Bus J, vol. 3, pp. 70-85, 2017.

[8] C. Maia, G. Lunardi, A. Longaray, and P. Munhoz, "Factors and characteristics that influence consumers' participation in social commerce", Revista de Gestão, vol. 25, no. 2, pp.194-211, 2018.

[9] M.M.Yusof, J. Kuljis, R.J. Paul and L. Stergioulas, "An evaluation framework for health information systems: incorporating human, organizational and technology-fit factors (HOT-fit). Int J Med Inform, vol. 77, no.6, pp. 386-398, 2008.

[10] W.H. DeLone and E.R. McLean, "Measuring e-commerce success: applying the DeLone and McLean information systems success model". I J Electron Com, vol. 9, no. 1, pp. 32-47. 2004.

[11] M. Tajvidi, Y. Wang, N. Hajli and P. E. Love, "Brand value co-creation in social commerce: the role of interactivity, social support, and relationship quality". Comp Hum Behv, 2017.

[12] Z. Huang and M. Benyoucef, "From e-commerce to social commerce: A close look at design features" Electron Com Res Appl, vol. 12, no. 4, pp. 246-259, July 2013

[13] H. Xi, Z. Hong, J. Sun, X. Li, J. Wei and R. Davison, "Impulsive purchase behaviour in social commerce: the role of social influence". 20th Pacific Asia Conference on Information Systems (PACIS), Chiayi, Taiwan pp. 364, June 2016.

[14] J. Chen, and X. L. Shen, "Consumers' decisions in social commerce context: An empirical investigation". Decis Support Syst, vol. 79, pp. 55-64, 2015.

[15] Lages, C., Lages, C.R. and Lages, L.F. "The RELQUAL scale: a measure of relationship quality in export market ventures". J Bus Res, vol. 8, no. 8, pp. 1040-1048. 2005.

[16] N. Oly Ndubisi, "Relationship marketing and customer loyalty". Mar Int Plan, vol. 25, no. 1, pp. 98-106, 2007.

[17] W.H. DeLone and E.R. McLean, "The DeLone and McLean model of information systems success: a ten-year update". J Manage Inf Syst, vol. 19, no. 4, pp. 9-30, 2003.

[18] P.B. Seddon and M.Y. Kiew, "A partial test and development of the DeLone and McLean model of IS success". In J.I. DeGross, S.L. Huff, and M.C. Munro (eds.), Proceedings of the Int Conf Inf Syst. Atlanta, GA: Association for Information Systems, pp. 99-110. 1997.
[19] A. Rai, S.S. Lang and R.B. Welker, "Assessing the validity of information systems success models: an empirical test and theoretical analysis", Inf Syst Res, vol. 13, no. 1, pp. 50-69, 2002.

[20] J.Y. Lai, C.C. Yang and W.S. Tang, "Exploring the effects of dependability on enterprise applications success in e-business". SIGMISCPR'06 Proceeding, pp. 244-252, 2006.

[21] Molla, A. and Licker, P.S. "E-commerce systems success: an attempt to extend and respecify the DeLone and McLean model of IS success". J Electron Com Success, vol. 2, no. 4, pp. 1-11. 2001.

[22] C. Smith, "It's time for retailers to start paying close attention to social media". Bus Insider Int, June 2015.

[23] M.M. Yusof, "A case study evaluation of a Critical Care Information System adoption using the socio-technical and fit approach". Int J Med Inf, vol. 84, no.7, pp. 486-499, 2015.

[24] I. Brown and R. Jayakody. "B2C e-Commerce success: a test and validation of a revised conceptual model". Electron J Inf Syst Evaluat, vol. 11, no. 3, pp. 167-184, 2008.

[25] S. Petter, W. DeLone, and E. McLean, "Measuring IS success: models, dimensions, measures, and interrelationships". Eur J Inf Syst, vol. 17, pp. 236-263, 2008.

[26] J.F. Hair, W.C. Black, B.J. Babin, R.E Anderson and R. L. Tatham, "Multivariate data analysis", Upper Saddle River, NJ: Prentice Hall, 1998.

[27] N. Makmor, S.S.A. Syed Shah Alam and N. Abd Aziz. "Social support, trust and purchase intention in social commerce era", Int J Supply Chain Manage vol. 7, no. 5, pp. 572-581, Jan 2018.

[28] N.B. Makmor and Syed Shah Alam, S.S.A. "Attitude towards social commerce: A conceptual model regarding consumer purchase intention and its determinants", Int J Econ Res, vol. 14, no. 15, pp. 431-441, Jan 2017.

[29] Engku Alwi, S.S. and Tengku Wook, T.S.M. "Social presence model for e-commerce”, Jurnal Teknologi, vol. 77, no. 1, pp. 71-83, Nov 2015.

[30] C.Baethge, J. Klier and M. Klier, "Social commerce-state-of-the-art and future research directions", Electron Markets, vol. 26, no. 3, pp. 269-290, August 2016.

[31] T. Hariguna, and B. Berlilana. "Understanding of Antecedents to Achieve Customer Trust and Customer Intention to Purchase ECommerce in Social Media, an Empirical Assessment". Int J Electron Comp Eng, vol. 7, no. 3, pp. 1240-1245, 2017.

[32] E. Ozkan and M. Tolon. "The effects of information overload on consumer confusion: An examination on user generated content" Bogazici J, vol. 29, no. 1, pp. 27-51, July 2015. 